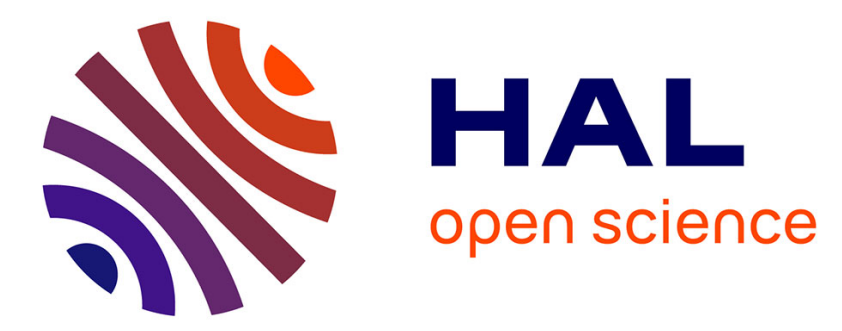

\title{
Carrier relaxation dynamics in InAs/InP quantum dots
}

\author{
Patrice Miska, Jacky Even, Olivier Dehaese, Xavier Marie
}

\section{To cite this version:}

Patrice Miska, Jacky Even, Olivier Dehaese, Xavier Marie. Carrier relaxation dynamics in InAs/InP quantum dots. Applied Physics Letters, 2008, 92, pp.191103. 10.1063/1.2909536 . hal-00492425

\section{HAL Id: hal-00492425 \\ https://hal.science/hal-00492425}

Submitted on 15 Jun 2010

HAL is a multi-disciplinary open access archive for the deposit and dissemination of scientific research documents, whether they are published or not. The documents may come from teaching and research institutions in France or abroad, or from public or private research centers.
L'archive ouverte pluridisciplinaire HAL, est destinée au dépôt et à la diffusion de documents scientifiques de niveau recherche, publiés ou non, émanant des établissements d'enseignement et de recherche français ou étrangers, des laboratoires publics ou privés. 


\title{
Carrier relaxation dynamics in InAs/InP quantum dots
}

\author{
P. Miska ${ }^{1,2}$, J. Even ${ }^{1}$, O. Dehaese ${ }^{1}$ and X. Marie ${ }^{3}$ \\ ${ }^{1}$ Laboratoire FOTON (INSA UMR CNRS 6082), 20 Avenue des Buttes de Coesmes, CS \\ 14315, 35043 Rennes Cedex, France. \\ ${ }^{2}$ Laboratoire de Physique des Matériaux, LPM - UMR CNRS 7556, Université Henry \\ Poincaré - Nancy I, Faculté des Sciences, Boulevard des Aiguillettes, BP 239, F-54506 \\ Vandouvre-lès-Nancy, France. \\ ${ }^{3}$ Université de Toulouse ; INSA, UPS - CNRS LPCNO, 135 Avenue de Rangueil, F- 31077 \\ Toulouse, France.
}

E-mail : patrice.miska@lpm.u-nancy.fr

PACS numbers : 78.67.Hc, 78.55.Cr, 78.47.Cd, 71.55.Eq, 73.21.La, 71.35.-y, 71.20, 71.48.jc

\begin{abstract}
The electronic properties of $\operatorname{InAs} / \mathrm{InP}(113) \mathrm{B}$ double-cap quantum dots (QDs) emitting around $1.55 \mu \mathrm{m}$ are investigated. The carrier dynamics in QDs is studied by non-resonant timeresolved photoluminescence (tr-PL) experiments. This analysis reveals the QD electronic structure and the transient filling of the confined QD levels. Under low excitation densities, the spontaneous exciton lifetime is estimated and compared to previous time-resolved resonant and non-resonant experiments. Under high excitation density, a direct Auger recombination effect is identified. The temperature analysis enables us to distinguish Auger and phonon-assisted relaxation processes.
\end{abstract}


Carrier Relaxation and band filling effects have been widely discussed in recent years $[1,2,3,4,5,6,7,8,9,10]$ due to their key role in the operation of optoelectronic devices such as, for example, quantum dot lasers. The detailed understanding of the relaxation processes from a more fundamental point of view is also a field of interest. Due to the quantum confinement, many electronic states are present inside the quantum dot (QD), and the carrier thermalization process has been studied. It has been shown that efficient thermalization can occur by multiphonon [11,12] or Coulomb interaction process [13]. State-filling effect has also been analyzed in many systems. The excited states photoluminescence (PL) signal has been clearly evidenced at high excitation density $[14,15,16,17,18,19]$. Auger relaxation effects have also been investigated. It has been shown it is the dominant effect under high excitation density [20,21]. Theoretical studies pointed out that Auger transfer is extremely fast for example in InAs/GaAs QDs [22,23].

Despite all these analyses, informations about the carrier dynamics in InAs/InP QDs are still lacking. These QDs are more suitable for telecom applications since they emit in the $1.55 \mu \mathrm{m}$ wavelength region. An original growth method has been proposed to obtain InAs/InP(113)B quantum dots with a tunable emission energy [24,29]. These structures, named double-cap quantum dots (DC-QDs), have been analyzed both theoretically $[25,26]$ and experimentally [27,28,29], and yield a laser emission at $1.55 \mu \mathrm{m}$ [29,30]. Confined electronic states have been identified, but informations on the dynamic properties of these levels are scarce. In this paper, we present a systematic study of the optical and electronic properties of the DC-QDs by using tr-PL spectroscopy. We deduce the exciton radiative lifetime of the confined levels and identify the relaxation processes.

The QDs are obtained by the spontaneous Stranski-Krastanow growth mode after the deposition of 2.1 InAs monolayers (ML) at $480^{\circ} \mathrm{C}$ on $\operatorname{InP}(311) \mathrm{B}$ substrate with a gas source molecular beam epitaxy system. The double-cap (DC) growth method [27] is then used to 
control the QD maximum height. The maximum height of the QDs we analyze here is of $2 \mathrm{~nm}$ [27], and the average QD diameter if of about $35 \mathrm{~nm}$. The surface density is of about $10^{10} \mathrm{~cm}^{-}$ ${ }^{2}$ [28]. Samples are characterized by time-resolved photoluminescence spectroscopy (tr-PL) at low temperature. The experiments are performed at $10 \mathrm{~K}$ using a $790 \mathrm{~nm}$ mode-locked TiSapphire laser (excitation in the InP barrier) producing 1.2 ps-long light pulses with a repetition rate of about $82 \mathrm{MHz}$. The tr-PL of the ensemble of QDs is then recorded by using either a streak camera or up-converting the luminescence signal in a nonlinear crystal with a time resolution of $20 \mathrm{ps}$ and $1.2 \mathrm{ps}$ respectively [28,34]. The luminescence peak of the chosen $2 \mathrm{~nm} \mathrm{DC}$ QD excitonic ground state $\left(\mathrm{QD}_{0}\right)$ is located at $0.94 \mathrm{eV}(1.32 \mu \mathrm{m})$ at $\mathrm{T}=10 \mathrm{~K}$. For this emission energy, the performances of the detectors are better than for DC QD with a maximum height equal to $3 \mathrm{~nm}$ emitting at $0.85 \mathrm{eV}(1.55 \mu \mathrm{m}$ at room temperature).

Tr-PL spectra obtained by the up-conversion set-up for various times after excitation are shown on figure 1 . The spectra are fitted with three peaks at energy positions corresponding to the excitonic states recorded in our previous studies [27] : the QD excitonic ground state $\left(\mathrm{QD}_{0}\right)$ at $0.94 \mathrm{eV}$, the $\mathrm{QD}$ first excited excitonic state $\left(\mathrm{QD}_{1}\right)$ at $0.99 \mathrm{eV}$ and the wetting layer excitonic ground state (WL at $1.05 \mathrm{eV})$. We can notice that at short times $(\mathrm{t} \sim 10$ ps), the emission of the WL state is the most important one. The $\mathrm{QD}_{0}$ ground state emission is however also observed, due to the possible direct carrier injection channels from the barrier to the $\mathrm{QD}_{0}$ state. For longer times, the carrier population in high energy states diminish either by light emission or by relaxation to the ground state $\mathrm{QD}_{0}$. A systematic study was performed with the streak camera. Spectra obtained at $10 \mathrm{~K}$ with various optical excitation densities for a long time (1650 ps) after excitation are reported in Fig. 2-a. These spectra are very similar whatever the excitation density is. They are equivalent to the one obtained at short times after excitation with a low incident optical power (figure 2-b). In this case indeed (150 ps, 16 $\left.\mathrm{W} . \mathrm{cm}^{-2}\right)$, the luminescence of the QD excitonic ground state $\left(\mathrm{QD}_{0}, 0.94 \mathrm{eV}\right)$, and the wetting 
layer (WL, $1.05 \mathrm{eV}$ ) are observed. When the excitation density increases, from 45 to 57 $\mathrm{W} . \mathrm{cm}^{-2}$, a luminescence signal appears at about $0.99 \mathrm{eV}$. It corresponds to the luminescence of the QD first excited state $\left(\mathrm{QD}_{1}\right)$ also identified in ref. 27. Then, when the excitation density is further increased, we observe a stabilization of the careers in the WL and the $\mathrm{QD}_{1}$ states, and then an corresponding intense luminescence. This behavior reveals the progressive filling of the $\mathrm{QD}_{1}$ and the $\mathrm{QD}_{0}$ levels. This analysis shows that the state filling plays an important role in the QD dynamics and emission properties. It can, for instance, explain the slight shift to high energies of the $\mathrm{QD}_{0}$ peak that can be observed in Fig. 2-a at long times after excitation for high exciation densiy. We have performed an estimation of the average number of excitons per QD produced by the optical excitation. It can be estimated with :

$$
N_{0}=\frac{P_{e x c}}{f h \nu} T_{\text {trans }}\left(1-e^{-\alpha L}\right)
$$

with $P_{e x c}$ the average excitation density, $h v$ the energy of incident photons, $f$ the laser repetition rate, $\alpha$ the absorption coefficient of the $\operatorname{InP}$ barrier $\left(\sim 10^{4} \mathrm{~cm}^{-1}\right), \mathrm{L}$ the $\operatorname{InP}$ barrier thickness $(30 \mathrm{~nm})$ and $T_{\text {trans }}$ the air/InP interface transmission coefficient. The filling of the $\mathrm{QD}_{1}$ level observed at an optical density of $45 \mathrm{~W} . \mathrm{cm}^{-2}$ corresponds here to an average exciton number per dot of 3 . It shows that the filling of the $\mathrm{QD}_{1}$ level is associated mainly to a saturation of the $\mathrm{QD}_{0}$ level after formation of the biexciton ground state.

We have also performed an analysis of the $\mathrm{QD}_{0}$ level radiative lifetime. Many studies have already been done yet in quantum wires [31] and quantum dots [32,33]. A direct experimental method is to use resonant excitation [34, 35]. In a pump-probe experiment, we have already studied DC-QD but emitting at $0.8 \mathrm{eV}$ at room temperature [35]. In the present work, we study the $\mathrm{QD}_{0}$ radiative lifetime of our DC-QD with non-resonant excitation measurements. In addition to the radiative process, relaxations from higher energy states and saturation of the ground state must be taken into account in these conditions. As the capture 
process to the $\mathrm{QD}_{0}$ state depends on the excitation density, we analyzed the $\mathrm{QD}_{0}$ decay time under low excitation density. The measured $\mathrm{QD}_{0}$ decay times are reported in Fig. 3 as a function of the excitation density and of the calculated number of exciton per QD. Under low excitation density, when the average number of carriers per dot is about 1 , the decay time is constant, of about $\tau \sim 1150$ ps. Under this regime, the $\mathrm{QD}_{0}$ level is not saturated (the average population per dot is smaller than 1), and we assume then that the exciton recombines with a characteristic time close to the radiative lifetime. This value has been compared to theory. In the strong confinement regime, the spontaneous emission rate is given by the Einstein's coefficient :

$$
A=\frac{1}{\tau_{Q D}^{r a d}}
$$

This coefficient can be written by considering only a transition between the electron and the heavy-hole $[34,36]$ :

$$
\frac{1}{\tau_{\text {rad }}}=\frac{n_{o p} e^{2} \omega_{0} E_{p}}{3 m_{0} h c^{3} \varepsilon_{0}}\left|\left\langle F_{C} \mid F_{V}\right\rangle\right|^{2}
$$

The envelope wave function overlapping coefficient $\left|\left\langle F_{C} \mid F_{V}\right\rangle\right|^{2}$ is calculated using a model described elsewhere [28]. We find $\left|\left\langle F_{C} \mid F_{V}\right\rangle\right|^{2}=0.92$ for the fundamental transition. The use of the Kane's energy $E_{p}=21.1 \mathrm{eV}$ and the InAs optical index $n_{o p}=3.9$ leads to the $1 \mathrm{se}-1 \mathrm{sh}$ radiative lifetime values of $1200 \mathrm{ps}$ for QD with a height of $2 \mathrm{~nm}$ and a diameter of $35 \mathrm{~nm}$. This calculated value is in very good agreement with the measured one.

The different rise and decay times measured at energies corresponding to the WL, $\mathrm{QD}_{0}$, and $\mathrm{QD}_{1}$ levels suggest the presence of cascade relaxation path. Moreover, we observed variations of rise and decay times measured under different temperature and excitation 
regime. This could be interpreted as the coexistence of two relaxation processes : Auger and phonon relaxation processes. To check this point, a detailed study has been done by measuring the tr-PL rise times $\tau_{r}^{Q D_{0}}$ (Fig. 4-a) and $\tau_{r}^{Q D_{1}}$ (Fig. 4-b) of $\mathrm{QD}_{0}$ and $\mathrm{QD}_{1}$ levels respectively as a function of both excitation density and temperature. Under high excitation density, the measured rise times of both levels are independent of temperature ( $\tau \sim 30 \mathrm{ps})$; it is probably limited by the time-resolution of the Streak camera set-up. The Auger relaxation process is dominant in this regime, yielding a very fast relaxation process. On the contrary, under weak excitation density, the rise times decrease with temperature. This reveals a strong influence of the phonon relaxation which is the dominating process in this regime. This behavior has been observed in InAs/GaAs quantum dots [2]. It has been shown that multiphononic relaxation process is strongly temperature dependent ; different types of phonons are present in this last system, leading to a reinforcement of the effective electronphonons coupling [37,38] and the possibility of multiphononic relaxation [39]. Theoretical studies have shown that the Huang-Rhys factor, representing the strength of the electronphonon coupling, increases with the size of the dot. Experimental results also confirm that this factor is enhanced by a factor 5 in InAs/GaAs quantum dots in comparison with bulk InAs [37]. These interpretations could explain the strong influence of phonons in exciton relaxation in our system. In a study of InAs/GaAs QD combining quasi-resonant and non-resonant TRPL experiment, Ohnesorge et al [2] have dissociated the relaxation process (phonon and Auger) of carriers. They used a three level model involving the GaAs matrix and two confined states in the InAs QD. This model can be considered as equivalent to ours if we take into account three levels constituted by the WL and the two QD confined states $\mathrm{QD}_{0}$ and $\mathrm{QD}_{1}$. They showed that, under weak excitation density, the rise time of the fundamental $\tau_{r}^{Q D_{0}}$ level can be written :

$$
\tau_{r}^{Q D_{0}}=\tau_{r}^{Q D_{1}}+\tau_{Q D_{1} \rightarrow Q D_{0}}
$$


This equation corresponds, according to them, to a cascade relaxation of excitons between the three considered levels assisted by phonon emission. Ohnesorge et al. then analyzed the effect of optical excitation density. They evidenced that, under strong excitation regime, luminescence decay time of the barrier $\tau_{B a r r i e r \rightarrow Q D_{1}}=\tau_{r}^{Q D_{1}}$ is close to $\tau_{r}^{Q D_{0}}$, the rise time of the fundamental level. Thus, they evidenced a direct Auger effect responsible for the direct capture from the barrier into the dot. The relation $\tau_{r}^{Q D_{0}} \rightarrow \tau_{r}^{Q D_{1}}$ implies then, according to equation (2), $\tau_{Q D_{1} \rightarrow Q D_{0}} \rightarrow 0$ under strong excitation regime. Moreover, the decay time of the first excited level $\mathrm{QD}_{1}$ can be written :

$$
\frac{1}{\tau_{d}^{Q D_{1}}}=\frac{1}{\tau_{Q D_{1} \rightarrow Q D_{0}}}+\frac{1}{\tau_{\text {spon }}^{Q D_{1}}}
$$

Then, if the condition $\tau_{Q D_{1} \rightarrow Q D_{0}} \rightarrow 0$ is realized, that is to say that a direct efficient Auger effect can occur, one can induce it yields a decrease of the $\mathrm{QD}_{1}$ photoluminescence level decay time. We can approximate our system as equivalent to the one described in Ref. 2: three levels corresponding to a WL level and two QD confined states. The $\mathrm{QD}_{1}$ decay times have been measured and the values reported in Fig. 4-c for different excitation powers. The spectra clearly show a reducing of the $\mathrm{QD}_{1}$ decay time. This behavior, if we rely on the results of Ohnesorge et al., evidence then in our three level system the presence of a direct Auger relaxation effect, where carriers directly relax from the $\mathrm{WL}$ into the $\mathrm{QD}_{0}$ level.

\section{Conclusion}

We analyzed the carrier relaxation processes in $\operatorname{InAs} / \operatorname{InP}(113) \mathrm{B}$ double-cap quantum dots. We showed the progressive filling of the identified confined levels $\mathrm{QD}_{0}$ and $\mathrm{QD}_{1}$ with the number of photo-generated carriers. The $\mathrm{QD}_{1}$ level starts filling with an average number of carriers per dot of about 3. We have also measured the QD fundamental level radiative 
lifetime which is in agreement with the theoretical value. By varying both temperature and optical excitation density, we managed to dissociate the Auger relaxation process from phonon relaxation process in our three level system. The analysis of the $\mathrm{QD}_{1}$ photoluminescence decay time with the excitation density has confirmed the presence of a direct Auger effect, responsible for the direct capture of carrier from the WL into the QD fundamental level. 
References :

${ }^{1}$ F. Adler, M. Geiger, A. Bauknecht, F. Scholz, H. Schweizer, M. H. Pilkuhn, B. Ohnesorge and A. Forchel, Appl. Phys. 80, 4019 (1996).

${ }^{2}$ B. Ohnesorge, M. Albrecht, J. Oshinowo, A. Forchel and Y. Arakawa, Phys. Rev. B 54, 11532 (1996).

${ }^{3}$ D. Morris, N. Perret and S. Fafard, Appl. Phys. Lett. 75, 3593(1999).

${ }^{4}$ R. Ferreira and G. Bastard, Physica E 7, 342 (2000).

${ }^{5}$ R. Ferreira and G. Bastard, Appl. Phys. Lett. 74, 2818 (1999).

${ }^{6}$ R. Heitz, M. Veit, N. N. Ledentsov, A. Hoffmann, D. Bimberg, V. M. Ustinov, P. S. Kop'ev and Zh. I. Alferov, Phys. Rev. B 56. 10435 (1997).

${ }^{7}$ M. Persson, N. Panev, L. Landin, S. Jeppesen and M.-E. Pistol, Phys. Rev. B 64 075309-1 (2001).

${ }^{8}$ U. Bockelmann and T. Egeler, Phys. Rev. B 46, 15574 (1992).

${ }^{9}$ S. Fafard, Z. R. Wasilewski, C. Ni Allen, D. Picard, P. G. Piva and J. P. McCaffrey, Superlattices and Microstructures. 25, 87 (1999).

${ }^{10}$ A.V. Uskov, J. McInerney, F. Adler, H. Schweizer and M. H. Pikuhn, Appl. Phys. Lett. 72, 58 (1998).

${ }^{11}$ S. Fafard, R. Leon, D. Leonard, J. L. Merz and P. M. Petroff, R. Heitz, M. Grundmann, N.

N. Ledentsov, L. Eckey, M. Veit, D. Bimberg, V. M. Ustinov, A. Y. Egorov, A. E. Zhukov, P. S. Kop'ev and Z. I. Alferov, Appl. Phys. Lett. 68, 361 (1996).

${ }^{12}$ S. Raymond, S. Fafard, S. Charbonneau, R. Leon, D. Leonard, P. M. Petroff and J. L. Merz, Phys. Rev. B 52, 17238 (1995).

${ }^{13}$ Al. L. Efros, V. A. Kharchenko and M. Rosen, Solid State Commun. 93, 281 (1995). 
${ }^{14}$ S. Fafard, R. Leon, D. Leonard, J. L. Merz and P. M. Petroff, Phys. Rev. B 52, 5752 (1995).

${ }^{15}$ S. Fafard, Z. Wasilewski, J. McCaffrey, S. Raymond and S. Charbonneau, Appl. Phys. Lett. 68, 991 (1996).

${ }^{16}$ M. Grundmann, N. N. Ledentsov, O. Stier, D. Bimberg, V. M. Ustinov, P. S. Kop'ev and Z. I. Alferov, Appl. Phys. Lett. 68, 979 (1996).

${ }^{17}$ H. Lipsanen, M. Sopanen and J. Ahopelto, Phys. Rev. B 51, 13868 (1995).

${ }^{18}$ S. Raymond, S. Fafard, P. J. Poole, A. Wojs, P. Hawrylak, S. Charbonneau, D. Leonard, R. Leon, P. M. Petroff and J. L. Merz, Phys. Rev. B 54, 11548 (1996).

${ }^{19}$ A. Melliti, M. A. Maaref, B. Sermage, J. Bloch, F. Saidi, F. Hassen, H. Maaref, Physica E : Low-Dimensional Systems and Nanostructures 28, 22 (2005).

${ }^{20}$ B. Ohnesorge, M. Albrecht, J. Oshinowo, A. Forchel and Y. Arakawa, Phys. Rev. B 54 11532 (1996).

${ }^{21}$ D. Morris, N. Perret and S. Fafard, Appl. Phys. Lett. 75, 3593 (1999).

${ }^{22}$ R. Ferreira and G. Bastard, Physica E 7, 342 (2000).

${ }^{23}$ R. Ferreira and G. Bastard, Appl. Phys. Lett. 74, 2818 (1999).

${ }^{24}$ C. Paranthoen, C. Platz, G. Moreau, N. Bertru, O. Dehaese, A. Le Corre, P. Miska, J. Even, H. Folliot, C. Labbé, G. Patriarche, J. C. Simon and S. Loualiche, J. Cryst. Growth 251, 230235 (2003).

${ }^{25}$ J. Even, S. Loualiche, P. Miska, C. Platz, J. Phys. Condens. Matter 15, 8737-8752 (2003).

${ }^{26}$ C. Cornet, C. Platz, J. Even, P. Miska, C. Labbé, H. Folliot and S. Loualiche AIP Conference Proceedings 772, 787-788 (2005).

${ }^{27}$ P. Miska, C. Paranthoen, J. Even, O. Dehaese, H. Folliot, N. Bertru, S. Loualiche, M. Sénès and X. Marie, Semicond. Sci. and Technol. 17, L63 (2002). 
${ }^{28}$ P. Miska, J. Even, C. Paranthoen, O. Dehaese, A. Jbeli, M. Senès, X. Marie, Appl. Phys. Lett. 86, 111905 (2005).

${ }^{29}$ P. Miska, C. Paranthoen, J. Even, N. Bertru, A. Le Corre, O. Dehaese, J. Phys. : Condens. Matter 14, 12301 (2002).

${ }^{30}$ K. Veselinov, F. Grillot, P. Miska, E. Homeyer, P. Caroff, C. Platz, J. Even, X. Marie, O. Dehaese, S. Loualiche, A. Ramdane, Optical and Quantum Electronics 38, 369-379 (2006).

${ }^{31}$ J. Bellessa, V. Voliotis, R. Grousson, X. L. Wang, M. Ogura, H. Matsuhata, Phys. Rev. B 58, 9933 (1998).

${ }^{32}$ D. S. Citrin, Supperlattices and Microstructures 13, 303 (1993).

${ }^{33}$ M. Sugawara, Phys. Rev. B 51, 10743 (1995).

${ }^{34}$ M. Paillard, X. Marie, E. Vanelle, T. Amand, V. K. Kalevich, A. R. Kovsh, A. E. Zhukov, and V. M. Ustinov, Appl. Phys. Lett. 76, 76 (2000).

${ }^{35}$ C. Cornet, C. Labbé, H. Folliot, P. Caroff, C. Levallois, O. Dehaese, J. Even, A. Le Corre, and S. Loualiche, Appl. Phys. Lett. 88, 171502 (2006).

${ }^{36}$ There is a mistake in the calculation of $1 / \tau_{\text {rad }}$ published in Ref. 34. An erratum will be published in APL soon. We use here the right formula.

${ }^{37}$ S. Hameau, Y. Guldner, O. Verzelen, R. Ferreira, J. Zeman, A. Lemaître and J.-M. Gérard, Phys. Rev. Lett. 83, 4152 (1999).

${ }^{38}$ R. Heitz, I. Mukhametzhanov, O. Stier, A. Madhukar and D. Bimberg, Phys. Rev. Lett. 83, 4654 (1999).

${ }^{39}$ J. Feldmann, S. T. Cundiff, M. Arzberger, G. Böhm, G. Abstreiter, J. Appl. Phys. 89, 1180 (2001). 


\section{Figure Caption}

Figure $1:$ PL spectra recorded at $10 \mathrm{~K}$ with the up-conversion setup at different times after excitation $(10,600$ and $1500 \mathrm{ps})$ for an excitation density of $\mathrm{I}_{\mathrm{exc}}=70 \mathrm{~W} \cdot \mathrm{cm}^{-2}$.

Figure 2 : Tr-PL spectra of $\mathrm{QD}_{1}$ level extracted from the streak camera data at $10 \mathrm{~K}$ for different excitation densities at (a) long times (1650 ps) and (b) short times (150 ps) after excitation. The excitation densities are $\mathrm{I}_{\mathrm{exc}}=16,45,57,74,155$ and $230 \mathrm{~W} \cdot \mathrm{cm}^{-2}$

Figure 3: $\mathrm{QD}_{0}$ decay time reported as a function of the optical excitation density and the calculated average number of exciton per QD. The inset shows a typical kinetics from which the decay times are measured. $\mathrm{T}=10 \mathrm{~K}$

Figure 4 : Evolution of the rise times a) $\tau_{r}^{Q D_{0}}$ of the fundamental $\left(\mathrm{QD}_{0}\right)$ and b) $\tau_{r}^{Q D_{1}}$ of the first exited state $\left(\mathrm{QD}_{1}\right)$ as a function of the temperature. The plotted data correspond to two excitation regimes: strong $\left(200 \mathrm{~W} \cdot \mathrm{cm}^{-2}\right)$ and weak excitation density $\left(18 \mathrm{~W} . \mathrm{cm}^{-2}\right)$. Dashed lines are a guide for the eye. Time evolution spectra recorded at $10 \mathrm{~K}$ and at the energy of the first excited state $\left(\mathrm{QD}_{1}\right)$ level for different excitation densities are reported in $\left.\mathrm{c}\right)$. 